\title{
Does family history of metabolic syndrome affect the metabolic profile phenotype in young healthy individuals?
}

Anna Lipińska ${ }^{1 *}$, Magdalena Koczaj-Bremer ${ }^{1}$, Krzysztof Jankowski ${ }^{1}$, Agnieszka Kaźmierczak ${ }^{1}$, Michał Ciurzyński ${ }^{1}$, Aisha Ou-Pokrzewińska', Ewelina Mikocka', Zbigniew Lewandowski ${ }^{2}$, Urszula Demkow $^{3}$ and Piotr Pruszczyk ${ }^{1}$

\begin{abstract}
Background: Early identification of high-risk individuals is key for the prevention of cardiovascular disease (CVD). The aim of this study was to assess the potential impact of a family history of metabolic syndrome (fhMetS) on the risk of metabolic disorders (abnormal body mass, lipid profile, glucose metabolism, insulin resistance, and blood pressure) in healthy young individuals.

Methods: We studied CVD risk factors in 90 healthy volunteers, aged 27-39 years; of these, 78 had fhMetS and 12 were without fhMetS (control group). Fasting serum lipids, glucose, and insulin levels were assayed, and anthropometric parameters and blood pressure using, an ambulatory blood pressure monitoring system, were measured. Nutritional and physical activity habits were assessed.

Results: Despite similar nutritional and physical activity habits, abnormal body mass was found in $53.2 \%$ of the fhMetS participants and $46.1 \%$ of the control participants $(p=0.54)$. The occurrence of obesity was $19.4 \%$ and $0 \%$, respectively $(p=0.69)$. Compared to the control participants, fhMetS was associated with significantly higher total cholesterol (5.46 $\mathrm{mmol} / \mathrm{L}$ vs. $4.69 \mathrm{mmol} / \mathrm{L}, \mathrm{p}<0.030$ ), low-density lipoprotein cholesterol ( $3.28 \mathrm{mmol} / \mathrm{L} \mathrm{vs} .2 .90 \mathrm{mmol} / \mathrm{L}, \mathrm{p}<0.032$ ), and non-high-density lipoprotein cholesterol ( $3.74 \mathrm{mmol} / \mathrm{L}$ vs. $3.25 \mathrm{mmol} / \mathrm{L}, \mathrm{p}<0.016$ ) levels, in addition to lower fasting glucose levels ( $4.51 \mathrm{mmol} / \mathrm{L}$ vs. $4.81 \mathrm{mmol} / \mathrm{L}, \mathrm{p}<0.042$ ). A positive correlation between fasting glucose and insulin levels $(r=0.28 ; p<0.015)$ was detected in the fhMetS participants. Higher mean daytime systolic blood pressure $(121.5 \mathrm{mmHg}$ vs. $113.3 \mathrm{mmHg}, \mathrm{p}<0.035)$, mean daytime diastolic blood pressure $(79.0 \mathrm{mmHg}$ vs. $74.5 \mathrm{mmHg}$, $p<0.045)$, and mean nighttime diastolic blood pressure ( $64.0 \mathrm{mmHg}$ vs. $59.5 \mathrm{mmHg}, \mathrm{p}<0.019$ ) were observed in the fhMetS group.
\end{abstract}

Conclusions: More than $50 \%$ of the fhMetS participants had excess weight or a lipid disorder, which may indicate an increased risk of cardiovascular disease and the need for regular ambulatory assessment of serum lipid concentrations in young people with a family history of MetS.

Keywords: Metabolic syndrome, Family history, Cardiovascular disease, Risk factors

\section{Background}

Atherosclerotic cardiovascular disease (CVD) continues to be a major cause of premature mortality worldwide and is considered by the Wold Health Organization (WHO) to be a major chronic, noncommunicable disease that results in global socioeconomic burden. Owing to the increasing

\footnotetext{
* Correspondence: anna.lipinska@wum.edu.pl

'Department of Internal Medicine and Cardiology, Medical University of Warsaw, Lindley'a 4, 02-005 Warsaw, Poland

Full list of author information is available at the end of the article
}

prevalence of risk factors, the incidence of CVD will also continue to increase [1]. The prevalence of atherosclerosis, even in early life, in addition to its dynamic course and unfavorable long-term prognosis, especially in young people, requires novel, easy, accessible, and more aggressive action in primary prevention. The WHO estimates that effective preventive strategies targeted at established, easy to assess, and modifiable risk factors such as smoking, obesity, dyslipidemia, diabetes, and arterial hypertension have the potential to reduce the 
global cardiovascular disease mortality rate by as much as $80 \%[2,3]$. However, the fundamental issue remains how to effectively identify groups of patients with increased cardiovascular risk, especially among the young and healthy. Several studies have shown that individuals with a family history of CVD are such a group [4]. The current 2012 European Guidelines on cardiovascular disease prevention in clinical practice note an increased cardiovascular risk in individuals with a family history of premature CVD. At the same time, the Systematic COronary Risk Evaluation (SCORE) system includes a general approach to family history, which tends to lower the associated cardiovascular risk [5].

Metabolic syndrome (MetS), includes several particularly unfavorable, proatherogenic, and interacting metabolic disturbances (visceral obesity, hyperinsulinemia, insulin resistance, elevated serum glucose, dyslipidemia, and arterial hypertension) and is a major cause of atherosclerotic cardiovascular disease and type 2 diabetes [6]. The presence of 3 or more of the MetS components increased the risk of cardiovascular disease 3-5 fold [7]. The incidence of MetS is also increasing, and studies indicate that the current incidence is $10-30 \%$ in various populations worldwide [7-10]. Studies have demonstrated a strong genetic basis for MetS components; therefore, young people with a family history of MetS could be regarded to be at higher cardiovascular risk and included in early preventive efforts to reduce those risk factors. However, evidence regarding the best methods to identify those at higher risk is lacking. We hypothesized that apparently healthy offspring of parents with MetS may demonstrate metabolic alterations that are typical for MetS. Owing to the increased prevalence of MetS in the general population, it is likely that clinicians will encounter increasing numbers of young patients with a family history of MetS. To the best of our knowledge, this population has not yet been analyzed. Therefore, the aim of this study was to characterize young, clinically healthy adults with a family history of MetS and assess the typical features of MetS (abnormal body mass, lipid and carbohydrate metabolic disorders, insulin resistance, and arterial hypertension) in this same group.

\section{Material and methods}

\section{Subjects and study design}

The study sample consisted of 90 healthy subjects (50 women, 40 men) aged 27 - 39 years with no clinical signs of atherosclerosis. To identify the subjects for the study group, we asked approximately 2000 patients from our Diabetic and Cardiac Outpatient clinics to refer their healthy adult children to our study. From the group of 211 patients who agreed to refer their children, we selected 160 patients with definitive MetS, and we screened their 150 children. Of these, 78 healthy adults offspring of the parents with confirmed MetS were enrolled in the study and considered the family history of metabolic syndrome (fhMetS) group. The control group included 12 persons with no family history of MetS who were selected from a group of 20 subjects who matched the demographic characteristics of the study group with a special focus on nutritional habits and physical activity. The exclusion criteria included: symptomatic atherosclerosis, i.e. coronary artery disease, arterial occlusive disease, or arterial hypertension; history of stroke or TIA; heart defect, heart failure, diabetes, thyroid disease, acute or chronic inflammatory process, connective tissue disorder, allergic disease, kidney disease (estimated glomerular filtration rate $<60 \mathrm{ml} / \mathrm{min}$ ), neoplasm, drug- or alcoholdependency, smoking, obstructive sleep apnea syndrome, or visceral obesity.

The project was conducted with approval from the Ethics Committee of Medical University of Warsaw. The participants provided written informed consent prior to participation.

MetS diagnosis was determined based on data in medical records (anthropometric data, biochemical data, and medical history). MetS was defined according to the Third Report of the National Cholesterol Education Program adult treatment panel III criteria of 2004, and required $\geq 3$ of the 5 equally weighted criteria: (1) waist circumference $>102 \mathrm{~cm}$ in men and $>88 \mathrm{~cm}$ in women, (2) blood pressure $>130 / 85 \mathrm{mmHg}$, or diagnosed and treated hypertension, (3) serum high density lipoprotein cholesterol (HDL-C) $<40 \mathrm{mg} / \mathrm{dL}(1.03 \mathrm{mmol} / \mathrm{L})$ in men and $<50 \mathrm{mg} / \mathrm{dL}(1.3 \mathrm{mmol} / \mathrm{L})$ in women, (4) serum triglycerides $(\mathrm{TG}) \geq 150 \mathrm{mg} / \mathrm{dL}(1.7 \mathrm{mmol} / \mathrm{L})$ or diagnosed and treated dyslipidemia, or (5) fasting serum glucose $\geq 100 \mathrm{mg} / \mathrm{dL}(5.6 \mathrm{mmol} / \mathrm{L})$ or diagnosed and treated diabetes [11]. The same criterion for waist circumference (WC) for Caucasians was defined in the 2009 scientific consensus [12].

All participants underwent an anthropometric assessment, which included measurements of WC, hip circumference, and weight. WC $(\mathrm{cm})$ was measured as the midpoint between the lowest rib and the iliac crest. The waist-hip ratio (WHR), and body mass index (BMI) were calculated. BMI, WHR, and WC are all established, simple clinical tests to assess excess body mass. BMI is the most common indicator used in clinical practice and epidemiological studies owing to its repeatability and its confirmed correlation with WC $[13,14]$. Abnormal body mass in the present study was defined as BMI $\geq 25 \mathrm{~kg} / \mathrm{m}^{2}$ and obesity as BMI $\geq 30 \mathrm{~kg} / \mathrm{m}^{2}$.

\section{Biochemical measurements}

Venous blood was collected in the morning, after fasting for at least 8 hours. All blood analyses were performed in the central laboratory of our hospital using Roche 
Diagnostic commercial kits and multichannel automatic analyzer Roche Cobas 6000 (c501 and e601). Fasting plasma glucose was measured using the enzymatic colorimetric hexokinase method (coefficient of variation [CV] less than 1.3\%). Total plasma cholesterol (TC) and TG were assayed using the enzymatic colorimetric method with cholesterolesterase oxidase and glycerol phosphate oxidase, respectively (CV less $1.6 \%$ for TC and less than $2.0 \%$ for TG). HDL-C was assayed using the enzymatic colorimetric method with polyethylene glycol (CV less than 1.5\%). Serum creatinine levels were assayed using the Jaffe method ( CV less than 3.5\%). Aspartate transaminase (AST) and alanine aminotransferase (ALT) were assayed using the International Federation of Clinical Chemistry method (CV less than $3.1 \%$ for AST and $1.4 \%$ for ALT). Uric acid was assayed using the enzymatic colorimetric method with uricase (CV less than 1.6\%). Glycated hemoglobin (HbA1c) was measured using a turbidimetric inhibition immunoassay (CV less than 2.0\%). High sensitivity C-reactive protein (hsCRP) was measured using an immunoturbidimetric latex method (CV less than 1.3\%). Low-density lipoprotein cholesterol (LDL-C) was calculated using the Friedewald formula (there were no subjects with TG $>400 \mathrm{mg} / \mathrm{dL}$ ). Non-HDL-C was calculated using the following formula: TC - HDL-C $=$ non-HDL-C. The insulin concentration was measured using an electrochemical method (Roche, ELECSYS 2010 syste), and the normal range is $2.5-24.9$ $\mu \mathrm{U} / \mathrm{mL}$. Insulin resistance was assessed by homeostasis model assessment-estimated insulin resistance (HOMAIR), which was calculated using the following formula: fasting insulin $(\mathrm{mU} / \mathrm{L}) \times$ fasting glucose $(\mathrm{mmol} / \mathrm{L}) / 22.5$ [15]

\section{Blood pressure measurements}

Ambulatory blood pressure monitoring (24-hour ABPM) was performed using the Spacelabs ABPM system every 20 minutes during the day $(6 \mathrm{am}-10 \mathrm{pm})$ and every 30 minutes at night $(10 \mathrm{pm}-6 \mathrm{am})$. The mean daytime systolic blood pressure (D-SBP), mean daytime diastolic blood pressure (D-DBP), mean nighttime systolic blood pressure (N-SBP), and mean nighttime diastolic blood pressure (N-DBP) were calculated. A resting electrocardiogram was performed using 12 standard leads and the Spacelabs device, and a treadmill test was conducted (Cambridge Hart CH 2000, Cardiac Diagnostic System USA). Echocardiograms were performed using a Phillips IE 33 system (Andeouver, Massachusetts, USA) with a $2.5-3.5 \mathrm{MHz}$ transducer.

\section{Nutritional habits and physical activity assessment}

All subjects completed standardized questionnaires regarding nutritional and physical activity habits [16,17]. Questions for nutritional habits included the number of meals per day, and their timing; frequency and amount of vegetables, fruits, sweets, and meat; and type and quantity of fluids consumed. Physical activity was classified as low (sedentary life-style), if physical exercises lasting at least 30 minutes was performed, (not at all, once a week, several times a month, or less frequently). The moderate classification was defined as physical exercises 2-3 times per week. The high classification was defined as $\geq 4$ times per week.

\section{Statistical analysis}

Data are presented as median and interquartile range. Statistical analysis was performed using the one-tailed Mann-Whitney test for comparison of quantitative variables between 2 groups. Association between quantitative variables were tested using Spearman correlation coefficients. All analyses were conducted using SAS 9.3 (SAS Institute, Cary, NC, USA).

\section{Results}

No differences were found between the groups in nutritional habits or level of physical activity. Approximately $20 \%$ of the subjects were moderately physically active, and none of the subjects participated in a high level of physical activity. There were no differences between the groups in age, weight, WC, BMI, or WHR, nor were there differences in the biochemical parameters (creatinine, uric acid, AST, ALT, erythrocyte sedimentation rate, white blood cell count, or hsCRP), which were within the normal ranges in both groups (Table 1). However, abnormal body mass, defined as $\mathrm{BMI} \geq 25 \mathrm{~kg} / \mathrm{m}^{2}$, was present in $53.2 \%$ of the fhMetS participants and $41.6 \%$

Table 1 Clinical characteristics of the studied groups (medians and IQR)

\begin{tabular}{llll}
\hline & fhMetS $(\mathbf{n}=\mathbf{7 8})$ & Control group $(\mathbf{n}=\mathbf{1 2})$ & $\mathbf{p}$ \\
\hline Age (years) & $35.0(31.0-39.0)$ & $32.5(27.0-37.0)$ & 0.256 \\
Body mass $(\mathrm{kg})$ & $75.5(59.0-93.0)$ & $69.5(58.0-81.0)$ & 0.267 \\
WC (cm) & $84.5(70.0-97.5)$ & $77.9(67.0-88.1)$ & 0.102 \\
BMI (kg/m $\left.{ }^{2}\right)$ & $25.3(21.9-28.7)$ & $23.6(22.5-26.0)$ & 0.499 \\
WHR & $0.9(0.8-0.9)$ & $0.8(0.8-0.9)$ & 0.365 \\
Creatinine (mmol/L) & $79.56(53.04-106.08)$ & $53.04(61.88-97.24)$ & 0.681 \\
eGFR (ml/min) & $84.4(74.9-92.7)$ & $82.3(71.7-89.9)$ & 0.420 \\
Uric acid (umol/L) & $261.71(220.0-339.0)$ & $261.72(237.92-285.5)$ & 0.879 \\
AST (U/L) & $19.0(16.0-24.0)$ & $17.1(13.0-22.0)$ & 0.248 \\
ALT (U/L) & $22.0(15.0-32.0)$ & $13.5(10.0-22.5)$ & 0.118 \\
ESR (mm) & $7.0(4.0-13.5)$ & $8.0(6.0-16.0)$ & 0.462 \\
WBC (G/L) & $6.1(5.1-7.2)$ & $6.9(5.2-9.7)$ & 0.310 \\
hsCRP (mg/L) & $1.3(0.8-2.5)$ & $1.1(0.4-5.8)$ & 0.704 \\
\hline WC- waist circumferen &
\end{tabular}

WC- waist circumference, BMI- body mass index, WHR- waist/hip ratio, GFR- glomerular filtration rate, AST-aspartate transaminase, ALT- alanine aminotransferase, ESR erytrocyte sedimentation rate, WBC- white blood cell count, hsCRP- high-sensitivity C-reactive protein. 
Table 2 Parameters of lipid and carbohydrate metabolism in studied groups (medians and IQR)

\begin{tabular}{|c|c|c|c|}
\hline & fhMetS $(n=78)$ & Control group $(n=12)$ & $\mathbf{P}$ \\
\hline $\mathrm{TC}(\mathrm{mmol} / \mathrm{L})$ & $5.46(2.21-6.08)$ & $4.69(1.27-5.55)$ & $<0.030$ \\
\hline LDL-C (mmol/L) & $3.28(2.68-3.95)$ & $2.90(2.39-3.07)$ & $<0.032$ \\
\hline $\mathrm{HDL}-\mathrm{C}(\mathrm{mmol} / \mathrm{L})$ & $1.46(1.17-1.51)$ & $1.51(1.16-1.65)$ & 0.976 \\
\hline nonHDL-C (mmol/L) & $3.74(3.30-4.63)$ & $3.25(2.64-3.70)$ & $<0.016$ \\
\hline TG $(\mathrm{mmol} / \mathrm{L})$ & $1.03(0.75-1.63)$ & $0.77(0.61-1.31)$ & 0.339 \\
\hline $\begin{array}{l}\text { Fasting glucose } \\
(\mathrm{mmol} / \mathrm{L})\end{array}$ & $4.51(4.29-4.73)$ & $4.81(4.54-5.01)$ & $<0.042$ \\
\hline $\begin{array}{l}\text { Fasting insulin } \\
(\mu \mathrm{U} / \mathrm{ml})\end{array}$ & $6.2(4.3-8.3)$ & $5.9(5.1-8.2)$ & 0.871 \\
\hline HOMA-IR & $1.24(0.82-1.83)$ & $1.27(1.01-1.94)$ & 0.748 \\
\hline $\mathrm{HbA1c}(\%)$ & $5.5(5.3-5.7)$ & $5.5(5.3-5.5)$ & 0.268 \\
\hline
\end{tabular}

TC- total cholesterol, LDL-C low- density lipoprotein cholesterol, HDL-C- high- density lipoprotein cholesterol, TG- triglyceride, HbA1c-glycated hemoglobin A1C.

of the control participants. Obesity $\left(B M I \geq 30 \mathrm{~kg} / \mathrm{m}^{2}\right)$ was noted in $19.4 \%$ of the fhMetS participants and none of the control group. The fhMetS group had significantly higher total cholesterol ( $\mathrm{p}<0.030)$, LDL-C $(\mathrm{p}<0.032)$, and non-HDL-C $(\mathrm{p}<0.016)$ values than the control group (Table 2), with $67.5 \%$ and $59.7 \%$ of the fhMetS participants and $41.6 \%$ and $33.3 \%$ of the control participants with a TC concentration $\geq 4.94 \mathrm{mmol} / \mathrm{L}$ and a LDL-C concentration $\geq 2.99 \mathrm{mmol} / \mathrm{L}$ respectively. In addition the fhMetS group was characterized by a higher frequency of participants with a TG concentration $\geq 1.71 \mathrm{mmol} / \mathrm{L}$ than the control group $(18.18 \%$ vs. $16.7 \%, \mathrm{p}=0.99)$, and a lower frequency of participants with an HDL-C concentration $\geq 1.30 \mathrm{mmol} / \mathrm{L}(62.3 \%$ vs. $66.6 \%, \mathrm{p}=0.99)$. The TG concentration was significantly higher $(\mathrm{p}<0.01)$ and HDL-C levels were significantly lower $(p<0.001)$ in the fhMetS participants with an abnormal body mass than the fhMetS subjects with a normal body mass. The atherogenic index (TG/HDL-C ratio) was significantly higher in the overweight and obese fhMetS participants compared to the fhMetS participants with normal body mass $(\mathrm{p}<0.002)$ (Table 3 ). The fhMetS subjects had significantly lower mean fasting glucose values $(4.51 \mathrm{mmol} / \mathrm{L}$ vs. $4.81 \mathrm{mmol} / \mathrm{L}$, $\mathrm{p}<0.042$ ) and higher fasting insulin values, although this difference was not significant (Table 2). A significant positive correlation between the fasting glucose and fasting insulin concentrations was detected in the fhMetS group $(r=0.28, p<0.015)$ but not in the control group. HbA1c levels were within the normal range in both groups $(\mathrm{p}=0.748)$. Significantly higher D-SBP, D-DBP and $\mathrm{N}-\mathrm{DBP}(\mathrm{p}<0.035, \mathrm{p}<0.045$, and $\mathrm{p}<0.019)$ were present in the fhMetS group than in the control group (Table 4). The frequency of the daytime SBP values $>140 \mathrm{mmHg}$ and DBP values $>90 \mathrm{mmHg}$ in the fhMetS group were $3.9 \%$ and $7.8 \%$ respectively, while the frequency of nighttime SBP values $>125 \mathrm{mmHg}$ and DBP values $>80 \mathrm{mmHg}$ were $5.1 \%$ and $1.3 \%$ respectively.

\section{Discussion}

Based on the comparison of young healthy adults who were children of parents with confirmed MetS, and ageand sex-matched healthy controls without a family history of MetS in the present study, we detected differences in some of the MetS components. Furthermore, more than half of the adults with a family history of MetS had abnormal body mass, and 1 in 5 were obese. Owing to the similarity in nutritional and physical activity habits between the groups, the high prevalence of abnormal body mass in the adults with a family history of MetS may reflect a predisposition to increased body weight in these individuals. A number of epidemiological studies have shown a relationship between excess body mass (overweight and obesity) and all-cause and cardiovascular mortality $[18,19]$. Moreover, adipose tissue, especially visceral adipose tissue, is related to abnormal lipid metabolism and induces insulin resistance in tissues. Atherogenic dyslipidemia is characterized by decreased HDL cholesterol concentrations, hypertriglyceridemia, and increased concentrations of small dense LDL particles. A strong positive correlation was found between the risk of cardiovascular disease and both TC and LDL concentrations in healthy men and women as well as in patients with symptomatic CVD [20]. Importantly, our results showed

Table 3 Lipid parameters ( $\mathrm{mmol} / \mathrm{L}$ ) in fhMetS depending on BMI; (medians and IQR)

\begin{tabular}{|c|c|c|c|c|c|c|}
\hline $\mathrm{mmol} / \mathrm{L}$ & $\begin{array}{l}\text { 1. Normal } \\
(n=37)\end{array}$ & $\begin{array}{l}\text { 2. Overweight } \\
(n=26)\end{array}$ & $\begin{array}{l}\text { 3. Obese } \\
(n=15)\end{array}$ & $\begin{array}{l}P \\
1 \mathrm{vs} 2\end{array}$ & $\begin{array}{l}P \\
\text { 1vs3 }\end{array}$ & $\begin{array}{l}P \\
2 v s 3\end{array}$ \\
\hline$\overline{\mathrm{TC}}$ & $5.41(4.77-6.02)$ & $5.54(4.81-5.98)$ & $5.07(4.21-6.45)$ & 0.798 & 0.681 & 0.749 \\
\hline LDL-C & $3.20(2.61-3.67)$ & $3.46(2.76-4.16)$ & $3.25(2.29-4.91)$ & 0.199 & 0.614 & 0.813 \\
\hline HDL-C & $1.69(1.44-2.03)$ & $1.25(1.14-1.46)$ & $1.12(0.88-1.35)$ & 0.0007 & 0.0001 & 0.041 \\
\hline nonHDL-C & $3.55(2.98-4.16)$ & $4.29(3.38-4.63)$ & $3.90(3.33-5.54)$ & 0.094 & 0.154 & 0.922 \\
\hline TG & $0.82(0.52-1.13)$ & $1.21(0.92-1.80)$ & $1.64(0.75-2.59)$ & 0.0007 & 0.012 & 0.627 \\
\hline TG/HDL ratio & $1.18(0.55-1.59)$ & $2.23(1.63-3.40)$ & $3.35(1.27-6.53)$ & 0.0001 & 0.002 & 0.294 \\
\hline
\end{tabular}

Normal -BMI $<25 \mathrm{~kg} / \mathrm{m}^{2}$, Overweight- BMI $\geq 25 \mathrm{~kg} / \mathrm{m}^{2}$, Obese- BMI $\geq 30 \mathrm{~kg} / \mathrm{m}^{2}$. 
Table 4 The characteristics of study groups according to ABPM values (medians and IQR)

\begin{tabular}{llll}
\hline $\mathbf{m m H g}$ & $\mathbf{f h M e t S}(\mathbf{n}=\mathbf{7 8})$ & Control group $(\mathbf{n}=\mathbf{1 2})$ & $\mathbf{p}$ \\
\hline D-SBP & $121.5(112.5-129.5)$ & $113.3(107.5-121.5)$ & $<0.035$ \\
D-DBP & $79.0(74.0-83.5)$ & $74.5(68.5-78.0)$ & $<0.045$ \\
N-SBP & $105.0(97.0-113.0)$ & $101.0(93.5-106.0)$ & 0.244 \\
N-DBP & $64.0(60.0-70.0)$ & $59.5(53.5-65.0)$ & $<0.019$ \\
\hline
\end{tabular}

D-SBP- daytime systolic blood pressure, D-DBP- daytime diastolic blood pressure, N-SBP- nighttime systolic blood pressure, N-DBP- nighttime diastolic blood pressure.

that more than $60 \%$ of the subjects with a family history of MetS had elevated TC $(\geq 4.94 \mathrm{mmol} / \mathrm{L})$ and LDL-C $(\geq 2.99 \mathrm{mmol} / \mathrm{L})$ levels in addition to a greater frequency of high TG concentrations and lower HDL-C values. As with $\mathrm{BMI}$, this is likely related to a family predisposition for abnormal lipid profiles, rather than differences in nutritional and physical activity habits. The 2012 European Guidelines for the prevention of cardiovascular diseases recommend the use of non-HDL-C as a parameter to quantify the amount of atherogenic lipoproteins containing apolipoprotein $\mathrm{B}$, which allows the prediction of CVD risk to a similar extent or even more accurately than LDL-C $[5,21]$. The present study reported a significantly higher mean non-HDL cholesterol concentration in the group with a family history of MetS than in the control group ( $\mathrm{p}<0.016)$. Regarding insulin levels, previous studies have demonstrated that, relationships exist between adipose tissue, insulin, the progression of insulin resistance, and hyperinsulinemia, although these relationships have not yet been well defined. A significant relationship has been demonstrated between insulin concentration and the risk of cardiovascular death, independent of other established risk factors, in people without diabetes [22]. Although the fasting glucose and insulin values were normal in both groups in the present study, a significant positive correlation was found between glucose and insulin concentrations in the group with fhMetS $(r=0.28$, $\mathrm{p}<0.015)$. This finding may indicate greater insulin resistance in tissues. However, HOMA-IR did not exceed 2.5 in any of the participants, and there was no differences in HOMA-IR between the groups. Experimental and clinical studies have also shown a relationship between adipose tissue and progression to and maintenance of elevated blood pressure [23]. The National Health and Nutrition Examination Survey III study results demonstrated that the prevalence of arterial hypertension increases with increasing BMI [24]. A positive correlation has also been found between BMI, lipid disorders, arterial hypertension, and the progression of atherosclerotic plaques in young people. In our study the ABPM resulted in significantly higher mean values of SBP and DBP in the daytime and DBP at nighttime in the participants with a family history of MetS, although less than $8 \%$ of these participants had elevated blood pressure. Population studies indicate that a family history of MetS is a marker of a strong genetic predisposition for cardiometabolic complications $[25,26]$. The results of the WHO-MONICA study, conducted in the French population, suggest that MetS should be assessed as an independent risk factor for the early onset of cardiovascular disease [25]. In the National Heart, Lung, and Blood Institute Family Heart Study, a family history of diabetes, and arterial hypertension resulted in a predisposition for carbohydrate and lipid metabolic disorders, which was especially true for non-obese individuals [26]. Such disorders appeared at a young age [27]. Similar results were demonstrated in the present study, in which there was a tendency for the early development of metabolic disorders in young persons with fhMetS. Collectively, the results of the present study indicate that abnormal body mass and lipid disorders, including those of total cholesterol and LDL cholesterol, are the most frequent metabolic disorders in young persons with a family history of MetS. This study has certain limitations, including a small sample size resulting from very rigorous inclusion and exclusion criteria intended to obtain homogenous groups. The parental history of MetS was confirmed in the fhMetS group and excluded in the control group.

However to the best of our knowledge, this is the first study documenting the typical metabolic alterations in MetS in healthy young adult children of parents with confirmed MetS. The results suggest that early screening for risk factors of MetS, such as overweight and hypercholesterolemia, should be conducted in this group. However, additional studies are required to confirm our findings.

\section{Conclusions}

Owing to the high frequency of overweight/obesity and lipid disorders, which are considered MetS risk factors for cardiovascular disease, in the healthy young adults with a family history of MetS, this group should be considered at high risk and undergo regular screening.

\section{Competing interests}

The authors declare that they have no competing interests.

\section{Authors' contributions}

$A L, P P$-acted as the principal investigators and contributed to study design and manuscript preparation, MK-B, KJ, AK, MC, AO-P, EM - assisted in individuals recruitment, data collection and discussions, ZL- performed the statistical analysis and participated in discussion, UD- contributed to laboratory analysis and participated in discussion. All authors read and approved the final manuscript.

\section{Acknowledgements}

The study was a part of research project supported with a grant of the Ministry of Science and Higher Education, Republic of Poland (N402 4702337). 


\section{Author details}

${ }^{1}$ Department of Internal Medicine and Cardiology, Medical University of Warsaw, Lindley'a 4, 02-005 Warsaw, Poland. 'Department of Epidemiology, Medical University of Warsaw, Oczki 3, 02-007 Warsaw, Poland. ${ }^{3}$ Department of Laboratory Diagnostics and Clinical Immunology of Developmental Age, Medical University of Warsaw, Marszałkowska 24, 00-567 Warsaw, Poland.

Received: 4 November 2013 Accepted: 6 June 2014

Published: 26 June 2014

\section{References}

1. SIGN (Scottish Intercollegiate Guidelines Network). Risk Estimation and the Prevention of Cardiovascular Disease. A National Clinical Guideline.2007. Report No 97. [http://www.sign.ac.uk/guidelines]

2. Tunstall-Pedoe $H$, Kuulasmaa $K$, Mähönen $M$, Tolonen $H$, Ruokokoski Amouyel P, for the WHO MONICA (monitoring trends and determinants in cardiovascular disease) Project: Contribution of trends in survival and coronary-event rates to changes in coronary heart disease mortality: 10 year results from 37 WHO MONICA Project populations. Lancet 1999, 353:1547-1557.

3. World Health Organization. Joint WHO/FAO Expert Consultation on Diet, Nutrition, and the Prevention of Chronic Diseases. 2002, Report No. 916. [http://www.who.int/dietphysicalactivity/publications]

4. Pandey AK, Pandey S, Blaha MJ, Agatston A, Feldman T, Ozner M, Santos RD, Budoff MJ, Blumenthal RS, Nasir K: Family history of coronary heart disease and markers of subclinical cardiovascular disease: Where do we stand? Atherosclerosis 2013, 228:285-294.

5. Perk J, De Backer G, Gohlke H, Graham I, Reiner Z, Verschuren M, Albus C, Benlian P, Boysen G, Cifkova R, Deaton C, Ebrahim S, Fisher M, Germano G, Hobbs R, Hoes A, Karadeniz S, Mezzani A, Prescott E, Ryden L, Scherer M, Syränne M, op Reimer WJ S, Vrints C, Wood D, Zamorano JL, Zannad F: European Guidelines on cardiovascular disease prevention in clinical practice (version 2012). The Fifth Joint Task Force of the European Society of Cardiology and other Societies on Cardiovascular Disease Prevention in Clinical Practice. Eur Heart J 2012, 33:1635-1702.

6. Gami AS, Witt BJ, Howard DE, Erwin PJ, Gami LA, Somers VK, Montori VM: Metabolic syndrome and risk of incident cardiovascular events and death. A systematic review and meta-analysis of longitudinal studies. JACC 2007, 49:403-414.

7. Lorenzo C, Williams K, HuntK J, Haffner SM: Trend in the prevalence of the metabolic syndrome and its impact on cardiovascular disease incidence: the San Antonio Heart Study. Diabetes Care 2006, 29:625-630.

8. Hu G, Qiao Q, Tuomilehto J, Balkan B, Borch-Johnsen K, Pyorala K: Prevalence of the metabolic syndrome and its relation to all- cause and cardiovascular mortality in nondiabetic European men and women. Arch Intern Med 2004, 164:1066-1076.

9. Park YW, Zhu S, Palaniappan L, Heshka S, Carnethon M, Heymsfield SB: The metabolic syndrome. Prevalence and associated risk factor findings in the US population from the Third National Health and Nutritional Examination Survey, 1988-1994. Arch Intern Med 2003, 163:427-436.

10. Hadaegh F, Hasheminia M, Lotfaliany M, Mohebi R, Azizi F, Tohidi M: Incidence of metabolic syndrome over 9 years follow-up; the importance of sex differences in the role of insulin resistance and other risk factors. PLoS One 2013, 8(9):e76304

11. Grudy SM, Brewer HB Jr, Cleeman Jl, Smith SC, Lenfant C Jr: Definition of metabolic syndrome: report of the National Heart, Lung, and Blood Institute/American Heart Association Conference on scientific issues related to management. Circulation 2004, 109:433-438.

12. Alberti KGMM, Eckel RH, Grundy SM, Zimmet PZ, Cleeman J, Donato KA Fruchart JCH, James WPTJ, Loria CM, Smith SC: Harmonizing the metabolic syndrome: a Joint Interim Statement of the International Diabetes Federation Task Force on Epidemiology and Prevention; National Hear, Lung, and Blood Institute; American Heart Association; World Heart Federation; International Society; and International Association for the Study of Obesity. Circulation 2009, 120:1640-1645

13. Liayo Y, Kwon S, Shaughnessy S, Wallace P, Hutto A, Jenkins AJ, Klein RL, Garvey WT: Clinical evaluation of adult treatment panel III criteria in identifying insulin resistance with dyslipidemia. Diabets Care 2004 27:978-983

14. Reaven GM: The metabolic syndrome: requiescat in pace. Clin Chem 2005, 51:931-938.
15. Matthews DR, Hosker JP, Rudenski AS, Naylor BA, Treacher DF, Turner RC: Homeostasis model assessment: insulin resistance and b-cell function from fasting plasma glucose and insulin concentration in men. Diabetologia 1989, 28:412-419.

16. Turconi G, Celsa M, Rezzani C, Biino G, Sartirana MA, Roggi C: Reliability of dietary guestionnaire on food habits, eating behaviour and nutritional knowledge of adolescents. Eur J Clin Nutr 2003, 57:573-763.

17. International Physical Activity Questionnaire IPAQ. [http://www.ipaq.ki.se]

18. Pischon $T$, Boeing $H$, Hoffman $K$, Bergmam M, Schulze MB, Overvad $K$, van der Schouw YT, Spencer E, Moons KGM, Tjønneland A, Halkjaer J, Jensen MK, Stegger J, Clavel-Chapelon F, Boutron-Ruault M-C, Chajes V, Linseisen J, Kaaks R, Trichopoulon A, Trichopoulos D, Bamia C, Sieri S, Palli D, Tumino R, Vineis P, Panico S, Peeters PHM, May AM, Bueno-deMesquita HB, van Duijnhoven FJB, et al: General and abdominal adiposity and risk of death in Europe. N Eng J Med 2008, 359:2105-2120.

19. Yusuf S, Hawken S, Ônpuu S, Bautista L, Franzosi MG, Commerford P, Lang CC, Rumboldt Z, Onen CL, Lisheng L, Tanomsup S, Wangai P Jr, Razak F, Sharma AM, Anand SS: Obesity and the risk of myocardial infarction in 27,000 participants from 52 countries: a case-control study. Lancet 2005, 366:1640-1649.

20. Neaton JD, Blackburn H, Jacobs D, Kuller L, Lee D-J, Sherwin R, Shih J, Stamler J, Wentworth D: Serum cholesterol level mortality findings for men screened in the Multiple Risk Factor Intervention Trial. Multiple Risk Factor Intervention Trial Research Group. Arch Intern Med 1992 152:1490-1500.

21. Robinson JG, Wang S, Smith BJ, Jacobson TA: Meta-analysis of the relationship between non-high density lipoprotein cholesterol reduction and coronary heart disease risk. J Am Coll Cardiol 2009, 53:316-322.

22. Jandeleit-Dahm KAM, Gray SP: Insulin and cardiovascular disease: biomarker or association? Diabetologia 2012, 55:3145-3151.

23. Bhagat $K$, Vallance $P$ : Inflammatory cytokines impair endothelium-dependent dilatation in human veins in vivo. Circulation 1997, 96:3042-3047.

24. Brown CD, Higgins M, Donato KA, Rohde FC, Garrison R, Obarzanek E, Horan M: Body mass index and prevalence of hypertension and dyslipidemia. Obesity Res 2000, 8:605-619.

25. Dallongeville J, Grupposo MC, Cottel D, Ferrieres J, Arveiler D, Bingham A, Ruidavets JB, Haas B, Ducimetière $P$, Amouyel P: Association between the metabolic syndrome and parental history of premature cardiovascular disease. Eur Heart J 2006, 27:722-728.

26. Hunt KJ, Heiss G, Sholinsky PD, Province MA, and the FHS Investigators: Familial History of Metabolic Disorders and the Multiple Metabolic Syndrome: The NHLBI Family Heart Study. Genet Epidemiol 2000, 19:395-409.

27. da Silva RC, Miranda WL, Chacra AR, Dib SA: Metabolic syndrome and insulin resistance in normal glucose tolerant Brazilian Adolescents with family history of type 2 diabetes. Diabetes Care 2005, 3:716-718.

doi:10.1186/1758-5996-6-75

Cite this article as: Lipińska et al:: Does family history of metabolic syndrome affect the metabolic profile phenotype in young healthy individuals? Diabetology \& Metabolic Syndrome 2014 6:75

\section{Submit your next manuscript to BioMed Central and take full advantage of:}

- Convenient online submission

- Thorough peer review

- No space constraints or color figure charges

- Immediate publication on acceptance

- Inclusion in PubMed, CAS, Scopus and Google Scholar

- Research which is freely available for redistribution 